\title{
An In-Depth Analysis on Sino-Foreign University Students' Perceived Stress
}

\author{
Tianai Yin
}

\author{
Kean University-Wenzhou \\ Corresponding author. Email: tianaiy@kean.edu
}

\begin{abstract}
The purpose of this study is to investigate the levels and sources of academic stress among students of Sino-foreign cooperative higher education (taking Wenzhou Kean University as an example). The research describes the causes and effects of stress and compares Wenzhou-Kean University (WKU) students' attitudes toward stress level, as well as finding coping strategies for stress management during the academic year 2021. Research problems include the demographic profile of respondents, perceived causes of stress, perceived effects of stress, significant differences in the stress level of respondents by academic/year level and gender, and respondents' preferred coping strategies. This research investigated 201 students at WKU, which consists of about $10 \%$ of the population through online questionnaires. Results from this research show that the stressors being surveyed ranking from the most to the least are academic competition from peers, interpersonal relationships, financial burden, and transition from high school to college. According to the survey, the major two aspects: life satisfaction and academic performance are almost equally affected by stress. Results also show that nearly half of the students prefer counseling as an intervention comparing to other coping methods.
\end{abstract}

Keywords: Stress Management, Causes of Stress, Effects of Stress, Coping Strategies, Stress Level.

\section{INTRODUCTION}

Stress generally exists in every aspect of social life, which is often referred to as the pressure of adults in work. However, with the development of society, a wider spread of stress is gradually influencing the younger generation to whom like students, especially college students, should not be underestimated. According to Murff [8], "the college student population often is subject to high level of stress" (2005, p.1). The stress of today's college students stems from a variety of factors, like the transition from high school to college, a lack of selfresilience, mental health issues, and financial burden.

As pointed by Mishra and Rath [9], "The transition from high school to college can be stressful for any college student and individuals experiencing a high level of stress were more likely to engage in unhealthy behaviors" (2015, p.1). Another reason that results in stress is a mental disorder. Studies have shown that approximately $20 \%$ of the world's adolescents have mental health and behavioral problems (UNICEF Report, 2011). Besides the former two causes of stress, the other factor is the student's lack of preparation for stress and self-resilience. As mentioned by Burwell [6], she stated that it is the parents' overprotection of children that leads to less resiliency and lower capability of holding anxiety in students (2018, p.154).

Fortunately, there are ways to help students who are suffering from various kinds of pressure. For example, counseling as an intervention is conducted at universities to ease student's pressure. Ryan [12] found that counseling can promote a students' perception of selfefficacy and self-worth, as well as controlling themselves when stressed out $(2005$, p. 2). This research paper aims at describing the causes of the stress of the students at Wenzhou Kean University and find methods to deal with it.

\subsection{Statement of Research Purpose}

The purpose of the study is to describe the causes and effects of stress and compare Wenzhou-Kean University (WKU) students' attitudes toward stress level, as well as finding coping strategies for stress management during the academic year 2021. 


\subsection{Research Questions and Hypotheses}

Research Question 1: What is the demographic profile of the respondents?

Research Question 2: What are WKU students' perceived causes of stress?

Research Question 3: What are WKU student's perceived effects of stress?

Research Question 4: The significant differences in the stress level of respondents by academic/year level and gender?

Research Question 5: What coping strategies do WKU students prefer for stress management?

Hypotheses: H0 (1) There is no significant difference in stress levels between different academic/year levels. H0 (2) There is no significant difference in stress levels between male and female students.

\subsection{Operational Definitions}

\section{Academic Performance:}

The measurement of student achievement across various academic subjects [4]. Measured by GPA in this study.

\section{Counseling:}

A professional relationship that empowers diverse individuals, families, and groups to accomplish mental health, wellness, education, and career goals [2].

Eustress:

The positive response to stress [10]

\section{Life Satisfaction:}

The extent to which a person finds life rich, meaningful, full, or of high quality [3]. Measured by a four-point Likert scale.

\section{Psychological Disorder:}

Psychological disorders or mental illnesses are conditions involving changes in emotion, thinking or behavior (or a combination of these) that are associated with distress and/or problems functioning in social, work, or family activities [1].

\section{Self-Resilience:} [15].

One's ability to adapt to stressful situations or crises

\section{LITERATURE REVIEW}

Today's educational environment is very different from what it used to be, and the problems students face have changed a lot compared with their parents. As parents pay more and more attention to their children's education, the proportion of intervention in their children's education is also increasing. However, the main body of study is the students themselves. At the university, they have to face all kinds of pressure sources from life and study without their parents' help, but they cannot handle stress. According to Brown [5], on behalf of the Higher Education Policy Institute, revealed that students are vulnerable when exposing to stress. Therefore, the ability to deal with stress alone when parents are not around is of great importance to contemporary college students, which can help to build their personal development. However, the first step to solve the problem is to understand the sources of college student stress. There are a variety of causes of stress among college students. As stated by Robotham [13], stressors related to the transition to university, being in a different country, and financial issues can cause distress for undergraduates.

The most well-known stressor is the transition from high school to college. Transition can be a hard time for undergraduates in terms of personal life and academic changes. Losing valuable networks and being disappointed by the negative academic change are the main reasons that cause distress. As stated by Peate [11], students often lose valuable networks when they move to university (2017), staying away from families and friends and facing an unfamiliar location where plenty of challenges waiting for them. Another common problem with the transition to college is the change in students' academic performance, which is usually a negative change. According to Burwell, falling grades can lead to anxiety [6].

The second stressor stems from a lack of selfresilience. In Scott's view, self-resilience refers to "one's ability to adapt to stressful situations or crises" [15]. A lack of resilient ability will possibly lead to excessive pressure. According to Burwell, "Today's young adults seem to arrive at college with less resiliency and a lower appetite for risk and failure" [6]. The overemphasis on success in contemporary education weakens students' understanding of the importance of failure, leaving them with little knowledge of how to properly view failure and learn from it, which ultimately leads to overwhelming stress.

Another common source of excessive stress comes from a psychological disorder, which is defined as the patterns of behavioral or psychological symptoms that impact multiple areas of life and creates distress for the person experiencing these symptoms. The prevalence of mental health disorders is much higher than expected. According to a study done by the National Union of Students in 2015, surveyed 1093 students in further and higher education revealed that 8 out of $10(78 \%)$ students had experienced mental health issues in the past year [11]. Poor mental health can aggravate students' perceived stress and affect their behavior, such as crying, abuse of self or others, smoking and irritability, and physiological symptoms include sweating, trembling, stuttering, headaches, weight loss or gain, body aches [7]. Thus, 
mental health is an important factor for successful stress management, and a corresponding coping strategy should be used as a tool for mental health.

The last stressor being reviewed relates to financial issues. Schafer pointed out that financial uncertainty can hurt individuals regardless of the temporary effect of stress [14]. To make matters worse, some students have staggering amounts of debt. According to Peate [11], students can take on tens of thousands of pounds of debt. As consequence, many undergraduates have to take up intense part-time jobs to pay off their debts, which aggravates the existing perceived stress level.

\section{RESEARCH METHODOLOGY}

\subsection{Research Design}

This research is descriptive-comparative research based on primary data obtained through online surveys. Participants are approximately $10 \%-12 \%$ of total students at Wenzhou-Kean University. The research lasts two weeks for data collection. Variables include demographic profile, the causes of stress, the effects of stress, differences of stress level in terms of gender and academic/year level, and coping strategies for stress management. Data will be analyzed using quantitative data analysis applications like Excel and SPSS.

\subsection{Study Design}

A cross-sectional study will be applied in this study. The study aims at finding the prevalence of stress among college students, with regard to both the study population and the time of the investigation. This study involves one contact with the study population to gather the required information.

\subsection{Study Population, Sample Size, and Sampling Technique}

In this study, the simple random sampling method is proposed to be used. Students in WKU would be chosen to participate in the research randomly. The research population constitutes 10 to 12 percent of all current students on campus, ranging from the first year to the fourth year. Simple random sampling is the appropriate sampling technique because every respondent (students) can be given an equal chance and probability to be chosen (Kumar, 2015).

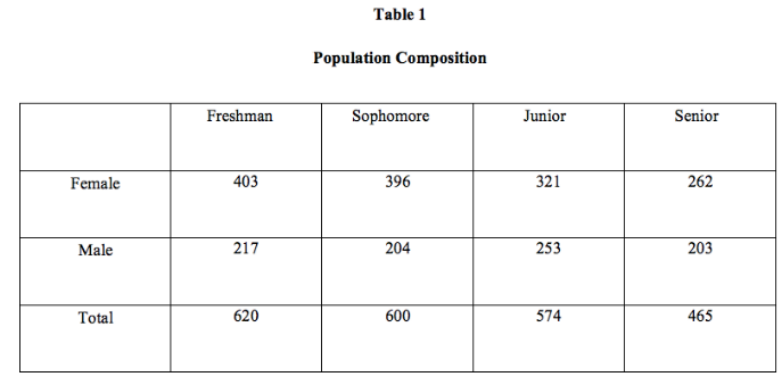

\subsection{Setting of the Study}

Wenzhou Ken university is a Sino-American cooperative university with an independent legal personality. The school-running level is dominated by undergraduate education, with appropriate development of postgraduate education, mainly focusing on economics and management, technology and mathematics, art design, education and psychology, health and rehabilitation science, and other professional groups. Currently, there are about 2000 students, including 15 international students, overseas Chinese from Hong Kong, Macao, Taiwan, and America. About 100 foreign full-time teachers are recruited by Ken university worldwide, offering 11 majors including accounting, finance, English, computer science and technology, international business, marketing, visual communication design, and management science.

The research population constitutes 10 to 12 percent of all current students on campus, including freshman, sophomore, junior, and senior who are randomly selected.

\subsection{Research Instrumentation}

The online questionnaire will be used in this study and mainly measure five parts around the attitude toward stress among undergraduates: demographic profile about respondents' personal information, respondents' perceived causes of stress, respondents' perceived effects of stress, differences in stress level regarding of academic/year level and gender, and respondents' preferred coping strategies. Peer critiquing was used to establish the validity and reliability of the constructed instrument.

In this research, the four-point attitudinal Likert Scale is applied to describe respondents' attitudes. It can specifically separate different levels of respondents' attitudes toward sub-objectives, and it is very appropriate for the measurement. The Likert Scale interpretation is shown below. 


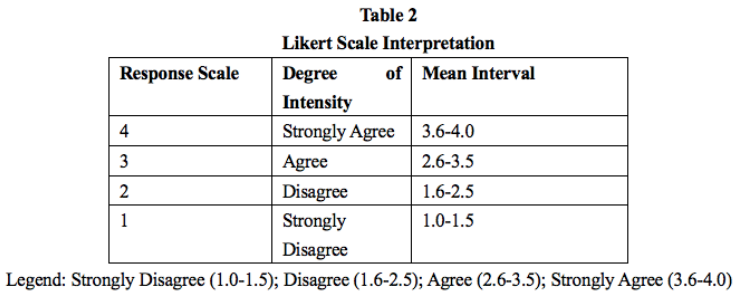

\subsection{Data Collection Procedure}

The researcher developed an online questionnaire using the website named Wenjuanxing. Then the researcher shares the questionnaire link through social media for target respondents to access and respond, which will further be used for the data analysis and results in interpretation.

Meanwhile, the researcher will carry out unstructured interviews using open-ended questions and interviews with 10 respondents to obtain more in-depth implications and enrich the discussion. The interview questions are as follows:

No.1 What are the reasons that you go/do not go to the counseling center to help you when you feel stressed?

No.2 Do you think that self-disclosure on social media can ease your stress?

No.3 Will you accept medical intervention to handle your stress?

\subsection{Data Analysis}

Descriptive and inferential statistics will be used in this study to provide a clear and in-depth data analysis. Data processing will use Microsoft Excel, SPSS, or to conduct relative charts and graphs.

Frequency and percentage will be used to describe the respondents' demographic profile.

Mean, standard deviation and ranking will be used to calculate the student's responses to the scaled questionnaires of stress among undergraduates at WKU.

T-test will be used to measure the differences by gender. ANOVA will be used to measure the differences by academic/year level.

\section{RESULTS AND DISCUSSION}

\subsection{Results}

Research Question 1: What is the demographic profile of the respondents in terms of?

1. Gender

2. Academic/Year Level

3. GPA
Figure 1 presents the Students' Distribution by Gender. Among the 201 respondents in the study, 147 or $73.13 \%$ were female, while 54 or $26.87 \%$ were male.

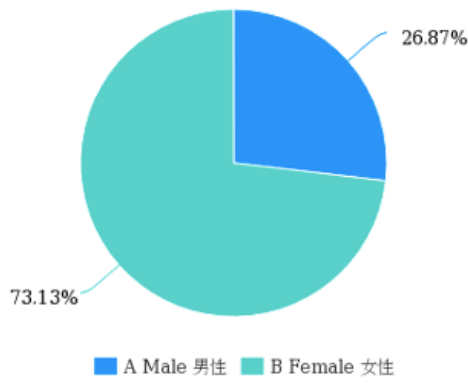

Figure 1-Students' Distribution by Gender

Figure 2 presents the Students' Distribution by academic/year level. Among the 201 respondents, 9 or $4.48 \%$ students were in the first year in WKU; followed by 135 or $67.16 \%$ were the second year in WKU; 23 or $11.44 \%$ of the third year, and 34 or $16.92 \%$ students were of the fourth year.

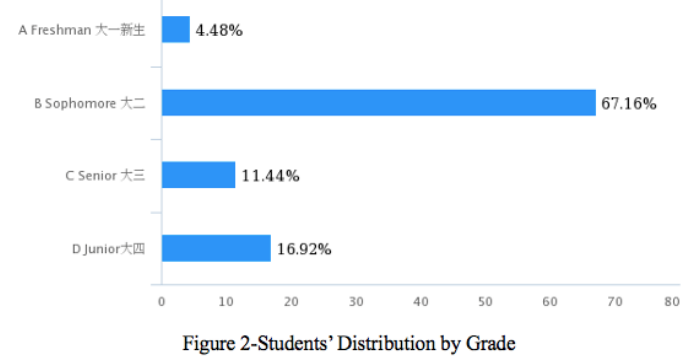

Figure 3 presents the Students' Distribution by GPA. Among the 201 respondents, there were 69 or $34.33 \%$ students who had their GPA between $3.5-4.0 ; 89$ or $44.28 \%$ students who had their GPA between $3.0-3.49$; 33 or $16.42 \%$ students who had their GPA between 2.5-2.99 and 10 or $4.98 \%$ students who had their GPA below 2.49 .

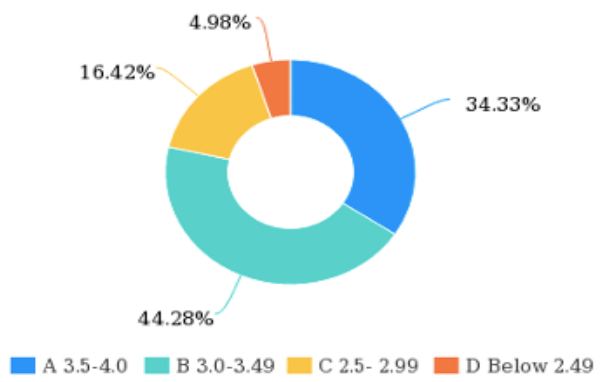

Figure 3-Students' Distribution by GPA

Research Question 2: What are WKU student's perceived causes of stress (stressors) in terms of? 1. Academic-related stressors (Transition from high school to college, competition from peers.) 
2. Social life-related stressors (Financial burden, interpersonal relationships)

Figure 4 shows The Distribution of Stressors of WKU students. According to this chart, academic competition from peers is the most popular one, with $172(85.57 \%)$ of the sample population selected. $94(46.77 \%)$ students voted interpersonal relationship as the main stressor, 83 $(41.29 \%)$ voted financial burden and $53(26.37 \%)$ voted to transition from high school to college as the main stressor. Competition from peers exceeds other stressors because a student living in an environment surrounded by classmates has to face a variety of competitions, like test ranking and exam scores.

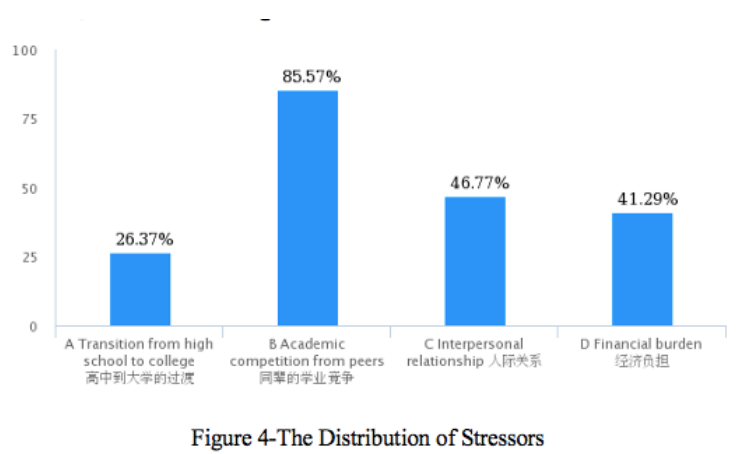

Research Question 3: What are WKU students' perceived effects of stress in terms of?

\section{Life satisfaction}

\section{Academic performance}

In order to obtain WKU students' perceived effects of stress, two aspects were used in the survey. The first one is life satisfaction and the second one is academic performance. This information is very important because these factors can tell how different levels of stress can affect the respondents' perceptions toward life and study.

Figure 5- Students perceived effects of stress by life satisfaction presents that $46(22.89 \%)$ students strongly agree that stress lowers their life satisfaction, 118 $(58.71 \%)$ agree, $36(17.91 \%)$ disagree and $1(0.5 \%)$ strongly disagree with the statement that stress lowers one's life satisfaction.

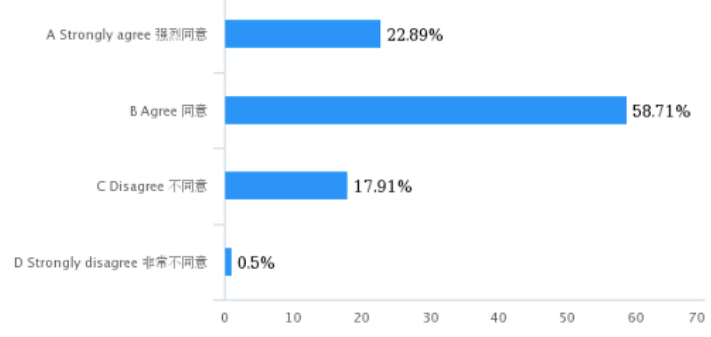

Figure 5- Students perceived effects of stress by life satisfaction
Figure 6 shows the distribution of perceived effects of stress on academic performance. According to the chart, $87(43.28 \%)$ students thought that stress has a negative effect on their study, $67(33.33 \%)$ students thought that stress has a positive effect on their study, and $47(23.33 \%)$ students thought there is no significant effect of stress on their study. It can be concluded that the percent of students who claimed stress influences their academic performance negatively was greater than that who claimed eustress. However, it is worth mentioning that despite the general recognition of the existence of stress in study and life, nearly one-fifth of students assumed that stress has no impact on their academic performance.

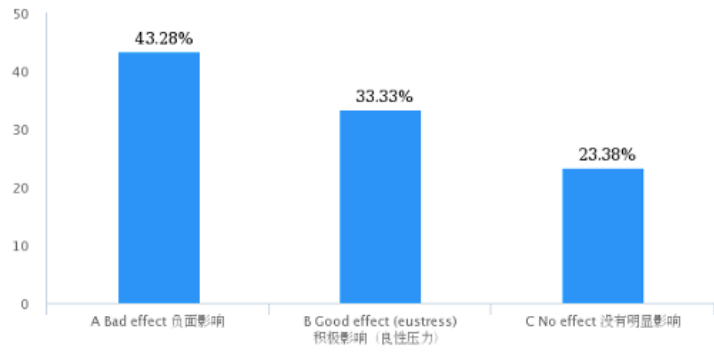

Figure 6- Students perceived effects of stress by academic performance

Research Question 4: Is there a significant difference in respondents' stress level by gender and academic/year level?

Ho: There is no significant difference in respondents' stress levels between male and female students.

Ho: There is no significant difference in respondents' stress level by academic/year level.

T-Test was performed to examine the degree of difference between the stress level by Gender. Table 3 presents the mean for male $(X=2.45283)$ and female $(X$ $=2.65540)$, and the P-value (.05332) of the students' gender in relation to stress level.

Table 3

Gender Mean Rank and its Significance in relation to Stress Level

\begin{tabular}{|c|c|c|}
\hline \multicolumn{2}{|c|}{ t-Test: Two-Sample Assuming Unequal Variances } & \multirow[b]{2}{*}{ Female } \\
\hline & Male & \\
\hline Mean & 2.452830189 & 2.65540541 \\
\hline Variance & 0.675616836 & 0.39065085 \\
\hline Observations & 53 & 148 \\
\hline Hypothesized Mean Difference & 0 & \\
\hline df & 75 & \\
\hline tStat & -1.633085975 & \\
\hline$P(T<=t)$ one-tail & 0.05332123 & \\
\hline tCritical one-tail & 1.665425373 & \\
\hline$P(T<=t)$ two-tail & 0.106642459 & \\
\hline t Critical two-tail & 1.992102154 & \\
\hline
\end{tabular}

The findings revealed an insignificant difference in the students' level of stress by Gender. Thus, the null hypothesis "There is no significant difference in respondents' stress level between male and female 
students." is thereby failed to be rejected. The finding is consistent in the study of Moseley [10] that there is no significant difference in stress levels between female students and male students.

T-Test was performed to examine the degree of difference between the stress level by academic/year level. Table 4 presents the mean for freshman (X = 2.5555), sophomore $(X=2.6000)$, junior $(X=2.5652)$ and senior $(X=2.6470)$, and the $P$-value (.0906) of the students' academic/year level in relation to stress level.

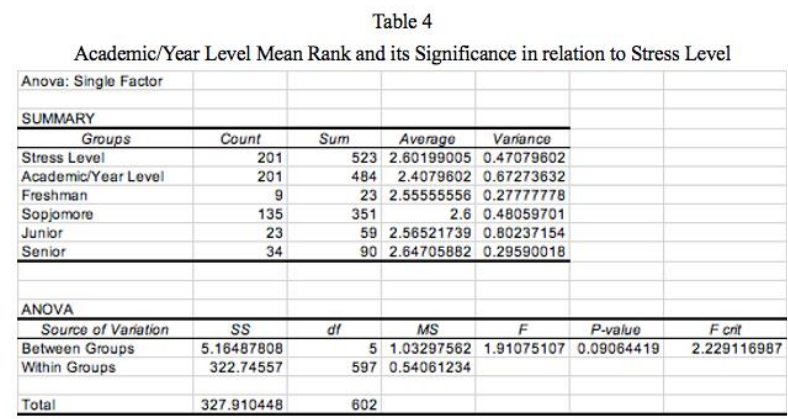

The findings revealed an insignificant difference in the students' stress level by academic/year level. Thus, the null hypothesis "There is no significant difference in respondents' stress level by academic/year level" is thereby failed to be rejected. Although the findings are contrary to the study of Moseley [10] that students in upper-grade levels had higher levels of eustress, however, since this study focused on stress instead of eustress, the results that there is no significant difference in stress level by grade level is acceptable. This broke our stereotype of higher stress levels for students in upper grades and vice versa, suggesting that students in different grades experience similar levels of stress, which may be due to undergraduates facing challenges at different grades that correspond to their mental level.

Research Question 5: What coping strategies do WKU students prefer for stress management in terms of counseling, online intervention, and others?

1. Counseling

2. Online intervention

3.Other (conducting self-control, doing sports, communicating with friends)

Figure 7 shows the overall percentage of the three categories. According to the pie chart, 93 (46.27\%) students prefer counseling, $35(17.41 \%)$ prefer online intervention, and 73(36.32\%) prefer other.

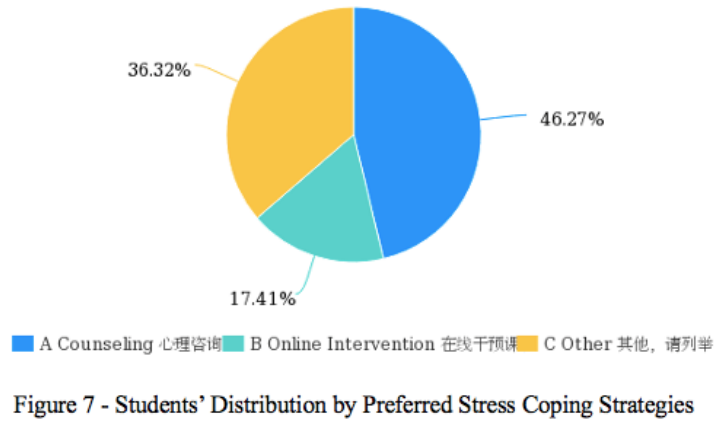

Figure 8 presents students' preferred coping strategy distribution by counseling. Among the 201 respondents, $31(19.4 \%)$ said that they had come to a counseling center, while $131(65.17 \%)$ said they had not and 39 $(19.4 \%)$ considered going in the future.

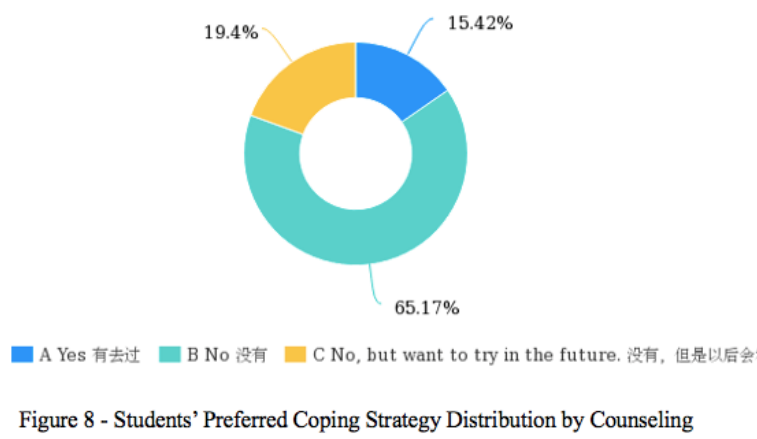

Figure 9 shows students' preferred coping strategy distribution by online intervention. Of the 201 respondents, $27(13.43 \%)$ had tried an online intervention to do self-stress management, while 141 (70.15\%) had not and $33(16.42 \%)$ considered doing one in the future.

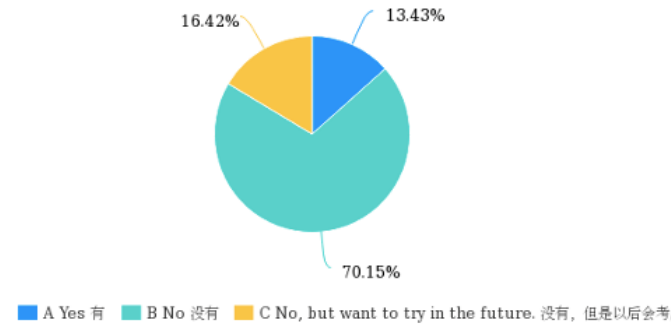

Figure 9-Students' Preferred Coping Strategy Distribution by Online Intervention

Figure 10 shows students' preferred coping strategy distribution by other methods. The total is over $100 \%$ because it is a multiple-choice question, considering that it is possible that some students had different ways of dealing with their stress. According to the chart, of the 201 respondents, $82(40.8 \%)$ showed their preference for doing sports, $107(53.23 \%)$ showed their preference for hanging out, $126(62.69 \%)$ showed their preference for sleeping, and $49(24.38 \%)$ preferred other activities. Choice "Other" is an open-ended question, among the 
students who chose "Other" and typed the answers, conducting self-control was the most popular choice. It can be concluded that although many students chose extroverted ways of dealing with stress, such as exercise and hanging out, more than half of them chose introverted ways of dealing with stress, such as sleeping or self-control.

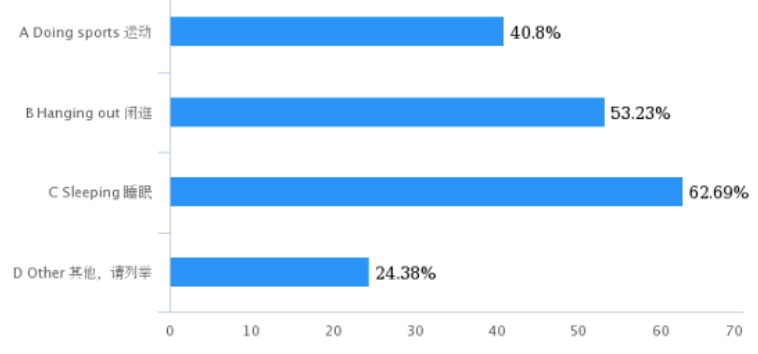

Figure 10-Students' Preferred Coping Strategy Distribution by Other Methods

\subsection{Discussion}

This study described the causes and effects of stress and compared WKU students' attitudes toward stress. According to the findings of the study, of the four facets of causes of stress (stressors), academic competition from peers ranked first, interpersonal relationships ranked second, financial burden ranked third and transition from high school to college ranked last. Two facets were used in evaluating the effects or influence of stress, life satisfaction, and academic performance. Results showed the majority of respondents think that stress lowers their life satisfaction with $46(22.89 \%)$ students strongly agree and $118(58.71 \%)$ agree. In terms of academic performance, the percent of students who claimed stress harms their academic performance was greater than that who claimed stress facilitates their study, with 87 (43.28\%) students thought that stress has a negative effect on their study, 67 (33.33\%) students thought that stress has a positive effect on their study.

For coping strategies, preferences of counseling and online intervention were surveyed. There was one thing in common between counseling and online intervention which referred that, although respondents who had been to a counseling center or used an online intervention both accounted for a small percentage of the sample, however, the percent of the respondents who answered "No, but want to try in the future" was greater than the percent of the respondents who answered "Yes" to counseling or online intervention.

The result of the t-test revealed that there was no significant difference in stress level by gender and academic/year level. However, Table 3 showed that female students have a higher level of stress with its mean $(X=2.6554)$ than male students $(X=2.4528)$. According to Table 4, the stress level of senior students ranked first, the sophomore ranked second, junior ranked third and freshman ranked last.

\section{CONCLUSIONS}

In the light of the findings of this study, the researcher was able to establish the following conclusions: Male students and female students have similar stress levels, there is a slight difference between gender, with a little higher stress level of female students but is not significant enough. Respondents of different grade levels have similar stress levels on average, with $\mathrm{X}$ ranges from 2.50 to 2.65. Thus, the null hypothesis "There is no significant difference of stress level between gender and different academic/year level" is thereby failed to be rejected. Therefore, it can be concluded that undergraduates of different grades and gender are generally experiencing higher levels of stress. Hence, it is necessary to care about the pressure of college students.

In order to evaluate the overall stress status of undergraduates and take corresponding measures, it is necessary to customize college students' stress level reports. With these data, school administrators can better help students reduce the burden and improve their academic performance and life satisfaction. It is suggested that school administrators conduct research and investigation according to students' feedback, which is crucial to help schools improve students' sense of belonging and self-worth.

The following strategies are recommended to enhance instructional effectiveness:

1. Provide professional psychological counseling teachers and psychological courses that teach students how to deal with a range of emotional problems such as stress and depression.

2. Strengthen quality education for students, not only emphasize the importance of academic achievements but also cultivate well-rounded, more engaged, and happier graduates.

3. Carry out campus collective activities to create students' sense of belonging on campus and help relieve the pressure of study and life.

By providing channels to collect relevant data on students' stress levels and optimizing the education system based on students' feedback, school leaders can understand the specific situation of students and provide references for carrying out relevant education courses. As a result, educational leaders and policymakers are recommended to manage and improve schools from a student perspective.

\section{ACKNOWLEDGMENTS}

I would like to express my sincere thankfulness to all those people who have supported me throughout the completion of my research. First, I have had a wonderful thesis committee that has supported and encouraged me 
throughout this process. I would also like to thank the participants who did the questionnaires I posted online, for they provided me with valuable primary data for my research. Additionally, I am thankful to be surrounded by my wonderful peers from WKU whom I consider mentors, colleagues, and friends.

\section{REFERENCES}

[1] American Psychiatric Association. (n.d.). What Is Mental Illness? Retrieved from https://www.psychiatry.org/patients-families/what-ismental-illness

[2] American Counseling Association. (n.d.). 20/20: consensus definition of counseling. Retrieved from https://www.counseling.org/about-us/about-aca/20-20a-vision-for-the-future-of-counseling/consensusdefinition-of-counseling

[3] American Psychological Association. (n.d.). APA dictionary of psychology: life satisfaction. Retrieved from https://dictionary.apa.org/life-satisfaction

[4] Ballotpedia. (n.d.). Academic performance. Retrieved from https://ballotpedia.org/Academic_performance

[5] Brown, P. (2016). The invisible problem: Improving student's mental health. HEPI (88). http://tinyurl.com/mzf2vg7

[6] Burwell, S. M. (2018). Generation stress: The mental health crisis on campus. Foreign Affairs, 97(6), 150-157. Retrieved from http://search.ebscohost.com/login.aspx?direct=true\&Aut hType $=$ cookie, ip, url,cpid \&custid $=$ keaninf $\& d b=a p h \& A$ $\mathrm{N}=132341938 \&$ site $=$ ehost-live\&scope $=$ site

[7] Misra, R., \& McKean, M. (2000). College students' academic stress and its relation to their anxiety, time management, and leisure satisfaction. American Journal of Health Studies, 16, 41-51.

[8] Murff, S. H. (2005). The impact of stress on academic stress in college students. ABNF Journal, 16(5), 102-104.

[9] Mishra, N., \& Rath, P. K. (2015). Impact of intervention on perceived stress of college students. Indian Journal of Health \& Wellbeing, 6(9), 859-864. Retrieved from http://search.ebscohost.com/login.aspx?direct=true\&Aut hType $=$ cookie, ip, url,cpid $\&$ custid $=$ keaninf $\& d b=a p h \& A$ $\mathrm{N}=111210403 \&$ site $=$ ehost-live\&scope $=$ site

[10] Moseley, A. C. (2018). Eustress in advanced placement (AP) and international baccalaureate (IB) students. ProQuest LLC. ProQuest Number:10977438
[11] Peate, I. (2017). Easing student stress. British Journal of Nursing, 26(7), 377. https://doi.org/10.12968/bjon.2017.26.7.377

[12] Ryan, J.A. (2005). Raising achievement with adolescents in secondary education-the school counsellor's perspective. British Educational Research Journal, 33(4), 551- 563.

[13] Robotham, D. (2008). Stress among higher education students: Towards a research agenda. Higher Education (00181560), 56(6), 735-746. https://doi.org/10.1007/s10734-008-9137-1

[14] Schafer, W. (1996). Stress Management for Wellness. (3rd ed.) Fort Worth: Harcourt Brace College Publishers.

[15] Scott, E. (2020). Why emotional resilience is a trait you can develop.Verywellmind.com. Retrieved from https://www.verywellmind.com/emotional-resilience-isa-trait-you-can-develop3145235\#: :text=Emotional\%20resilience $\% 20$ refers $\% 2$ 0to $\% 20$ one's, changes $\% 2 \mathrm{C} \% 20$ both $\% 20$ major $\% 20$ and $\%$ 20minor. 